\title{
Desafios da psicologia e da pesquisa no pós-COVID-19: um olhar a partir do contexto de Moçambique
}

\author{
Challenges for psychology and research \\ in the post-COVID-19 world: notes from \\ Mozambique
}

\author{
Augusto Joaquim Guambe (1) \\ Editor de Políticas Públicas na Revista Psicologia, Diversidade e Saúde. \\ Universidade Eduardo Mondlane (Maputo), Universidade Wutivi (Maputo). Moçambique. guambe26@gmail.com
}

O problema da COVID-19 (causada pelo novo corona vírus) declarada como uma pandemia pela OMS em 11 de março de 2020, desperta interesse em todos os campos do saber, sendo que a psicologia se coloca no lugar de privilégio pelo reconhecimento do seu papel interventivo na mitigação dos efeitos desta doença (Zanon et al., 2020).

A experiência que partilho é um olhar de um profissional que fala a partir da experiência vivida no trabalho assim como na colaboração com outros profissionais de psicologia que face a um problema de saúde pública concordaram em desenvolver uma ação voluntária tendo em vista contribuir para a resposta efetiva e significativa deste mal, uma vez que a cada dia se alastra em todos os cantos do mundo.

Estas experiências individuais dos profissionais de psicologia são partilhadas e discutidas numa rotina semanal entre os membros de um grupo de trabalho constituído por mais de 40 profissionais de psicologia, respeitando suas diferenciações em especialidades e escolas de formação.
Moçambique teve a informação de confirmação do primeiro caso da COVID-19 no dia 22 de Março do presente ano através das autoridades locais da saúde (MISAU, 2020). Seguidamente o Presidente da República reforçou as medidas de prevenção, tendo sido adoptado o isolamento social como a estratégia principal que foi desde a (1) suspensão das aulas em todos os níveis (do pré-escolar até ao universitário incluindo o ensino técnico profissional), com efeito a partir de 23 de Março; (2) a suspensão dos cultos religiosos, reuniões de vária natureza; (3) a rotatividade dos funcionários nos locais de trabalho; entre outras medidas (Decreto Presidencial no 11/2020 de Março, Declara o Estado de Emergência, por Razões de Calamidade Pública, em todo o território nacional. / COVID 19 / Início - Ministério da Indústria e Comércio, 2020).

Importa referir que as medidas de segurança avançadas pelo governo através dos Decretos que instituem o Estado de Emergência que inclui a três (3) prorrogações do mesmo até então, suscitaram a necessidade de várias iniciativas de prevenção da propagação da pandemia. Por parte do movimento de profissionais de psicologia, levou a 
planificação e disponibilização de assistência psicossocial, por ora privilegiando o uso das tecnologias de informação e comunicação (TIC).

O isolamento social gera problemas de tal maneira que "pesquisadores apontam que haverá sequelas da pandemia no desenvolvimento infantil e na saúde mental de crianças e adolescentes" (Militão, 2020). Em Moçambique em específico as pessoas buscam atendimento psicológico devido a dificuldades em lidar com o estresse, dificuldades em gerir a rotina das crianças no espaço doméstico, problemas conjugais que antes o casal encontrava refúgio no trabalho entre outras rotinas fora do espaço doméstico, entre outros problemas que afetam a saúde mental da população.

\section{Constrangimentos e Fragilidades}

Como uma classe profissional, reconhecemos a falta de experiência e (in)capacidade para atendimento e intervenção em situações de crise e emergência. Seguramente ninguém fica preparado à espera da crise para se reinventar, tal como foi o caso de Moçambique para com os profissionais de psicologia, mesmo sem querer deixar de destacar a experiências acumuladas e desenvolvidas para com as vítimas das cheias do ano 2000, no acidente de Tenga com o descarrilamento do comboio', explosão do paiol em 2007 em Maputo², os ciclones Idai e Kenneth no ano passado.

Mesmo com as adversidades acima relatadas, foi possível mobilizar quase 5 dezenas de Psicólogos voluntários por parte da Associação de Psicologia de Moçambique para dar resposta e suporte àqueles que necessitam de apoio para lidar com a nova vida imposta pela pandemia. Iniciativas similares também levadas a cabo por outras instituições, o exemplo das universidades visando prestar assistência psicológica em tempos de pandemia com recurso as $\mathrm{TCI}$.

\section{Que avaliação se faz da iniciativa de assistência psicossocial no âmbito da COVID-19?}

Apesar do esforço empreendido com destaque na avalanche dos serviços de Atendimento Psicológico gratuito e acessível para quase todas as camadas sociais, a adesão tem sido muito fraca: observando-se pouca demanda de pessoas/utentes ${ }^{3}$ na busca de atendimento. E este fato que nos leva a inferir que a utilidade da psicologia é pouco conhecida pela população. Pois, na visão de Araújo (2009), na tentativa de estabelecer uma critica a William Wundt:

É necessário, em primeiro lugar, entender o significado do termo "experiência" em Wundt. Para ele, a experiência em geral é um todo unitário e coerente, que pode ser concebido e elaborado cientificamente a partir de dois pontos de vista distintos, porém complementares: toda experiência pode ser analisada pelo seu conteúdo puramente objetivo (experiência mediata) ou subjetivo (experiência imediata). No primeiro caso, abstrai-se o sujeito da experiência e coloca-se toda a ênfase nos seus

objetos (mundo externo), enquanto que, no segundo caso, investigam-se os aspectos subjetivos da experiência e sua relação recíproca com todos os conteúdos da mesma (mundo interno) (p.211).

Diante da realidade dura que se apresenta e perante um conjunto de expetativas que parecem frustrar-se por parte dos profissionais de psicologia, a minha visão é que não olhemos para isso como uma fraqueza, mas sim que se encare como uma potência. E se assim for, que em conjunto façamos uma reflexão que nos oriente para caminhos capazes de desacomodar a psicologia das práticas positivistas e tradicionalista (cfr. Zuninga \& Guareschi, 2005).

Ademais, pensar numa psicologia que não se preocupa pelas classificações nosológicas dos problemas das pessoas devido ao prejuízo que estas denominações produzem na sociedade. O medo de ser timbrado com um transtorno/distúrbio faz com que as pessoas se afastem deste profissional. Uma preocupação que pareceu prioritária numa conversa com um utente:

Dr! Uma coisa que me preocupa bastante mesmo quando estou sozinho a reflectir sobre estas coisas que se passam comigo, é o medo de ficar completamente louco já que o médico que me receitou os medicamentos no hospital me falou que tenho depressão. Depois da consulta li coisas na internet sobre depressão e notei que é muito perigoso, acho que não vou aguentar. Prefiro morrer do que passar por aquilo tudo que li lá (Depoimento de um Jovem de 25 anos, trabalhador e estudante universitário).

1 Comboio significa trem (N.E.)

2 (Mundo, 2007)

3 Utente significa usuário (N.E.). 
Depoimentos como estes nos chamam a desafios sérios dentro do nosso exercício na profissão, tais relatos apelam-nos a pensar em como tornar a psicologia positivamente visível e acessível para a população. Lembrar que estamos a falar de um contexto em que existem outros saberes e práticas culturalmente acessíveis para as pessoas e que tem muita credibilidade pelo facto de dialogarem diretamente com todo um sistema de valores e de crenças desta população. Falo da medicina tradicional de Moçambique baseada em saberes tradicionais de plantas, das seitas religiosas neopentecostais, entre outros recursos visíveis.

Trabalhar as opiniões dos sujeitos implicados com a realidade produzindo subjetividades pode ser outra estratégia a ser capitalizada no exercício de inovar/ (re)inventar a psicologia e desacomodar as práticas que parecem menos funcionais (Guambe et al., 2018).

É certo que mesmo que se vença esta "guerra", a vida não voltará a ser como antes, daí a necessidade de a psicologia contribuir com formas e estratégias criativas de como lidar com o outro. Daí a indagação por exemplo: como será o contato social no pós-pandemia? Estas e outras questões não mencionadas devem pautar a nossa agenda para os tempos que vêm.

Os desafios para o sucesso nas intervenções emergenciais passam necessariamente por:

- Pensar na dificuldade de a psicologia, no contexto de Moçambique, onde há influência de fortes crenças instaladas pela cultura;

- Pensar na importância de não reduzir a psicologia a grandes patologias, associada ao medo dos rótulos;

- Reforçar o diálogo entre os diferentes campos da psicologia, incluindo pesquisa-intervenção;

- Criar mecanismos que orientam a prática da psicologia, visto que estamos sem uma Ordem para a nossa classe no país e consequentemente sentimo-nos vulneráveis e proteção em caso de problemas relacionados com a conduta ética e deontológica;

- Partilhar permanentemente os saberes versus harmonização das técnicas, metodologias e outros recursos para a prática.
De tantas coisas que relato nesta fala acredito que possivelmente a resposta da psicologia neste período de pandemia será mais evidente.

\section{Agradecimentos}

Este editorial originou-se a partir de comunicação do autor no Seminário Internacional sobre desafios da Psicologia no futuro pós-COVID-19, realizado em 17 de julho de 2020 no âmbito do Mestrado Profissional em Psicologia e Intervenções em Saúde da Escola Bahiana de Medicina e Saúde Pública. O seminário realizouse através de plataforma eletrônica de videoconferência.

\section{Referências}

Araujo, S. F. (2009). Uma visão panorâmica da psicologia científica de Wilhelm Wundt. Scientiae Studia, 7(2), 209-220. Recuperado de https://www.scielo.br/scielo. php?pid=S1678-31662009000200003\&script=sci_arttext . doi: $10.1590 /$ S1678-31662009000200003

Decreto Presidencial no 11/2020 de 30 de Março de 2020. Declara o Estado de Emergência, por Razões de Calamidade Pública, em todo o território nacional. / Covid 19 / Início-Ministério da Indústria e Comércio, Presidëncia da República de Mocambique (2020) (testimony of Imprensa Nacional). Recuperado de https://www.mic.gov. mz/por/covid-192/Decreto-Presidencial-n1-11-2020-deMarco-Declara-o-Estado-de-Emergencia-por-Razoes-deCalamidade-Publica-em-todo-o-territorio-nacional

Guambe, A. J., Fringe, J. J. S., \& Bicalho, P. P. (2018). PesquisaIntervenção e Produção da Subjectividade: Uma metodologia em Psicologia. Revista PSIQUE: Psicologia, Psiquiatria e Saúde Mental, 6, 11-19.

Hüning, S. M., \& Guareschi, N. M. F. (Orgs.). (2005). Foucault e a Psicologia. Abrapso Sul.

Militão, B. (2020, Junho 5). Isolamento social é fator de risco para a saúde mental das crianças [Internet]. Recuperado de https://jornal.usp.br/atualidades/isolamento-social-efator-de-risco-para-a-saude-mental-das-criancas/

Ministério da Saúde (MISAU) (2020). Primeiro caso de Coronavirus confirmado hoje em Moçambique [Internet]. Recuperado de http://www.misau.gov.mz/index.php/100-primeiro-casode-coronavirus-confirmado-hoje-em-mocambique 
Mundo (2007, março 23). Tragédia em Maputo [Web Notícias].

Recuperado de https://www.cmjornal.pt/mundo/detalhe/ tragedia-em-maputo

Zanon, C., Dellazzana-Zanon, L. L., Wechsler, S. M., Fabretti, R. R., \& Rocha, K. N. (2020). COVID-19: Implicações e aplicações da Psicologia Positiva em tempos de pandemia. Estudos de Psicologia, 37(e200072). Recuperado de https://www. scielo.br/scielo.php?script=sci_arttext\&pid=S0103166X2020000100506. doi: 10.1590/1982$0275202037 \mathrm{e} 200072$ 